\title{
Effect of soybean plant phenols and flavonoid on the mean leaf area consumed by Spodopteralitura and Spilosoma obliqua larvae
}

\author{
Anchala Nautiyal, Neeta Gaur, Kamendra Singh and Preeti Sharma \\ Department of Entomology, College of Agriculture, G.B. Pant University of Agriculture and Technology, \\ Pantnagar, U. S. Nagar -263145 (Uttarakhand), INDIA \\ *Corresponding author. E-mail: Anchala.nautiyal@gmail.com \\ Received: December 31, 2015; Revised received: July 4, 2016; Accepted: October 31, 2016
}

\begin{abstract}
The aim of the present investigation was to study the effect of soybean plant phenols and flavonoid content on the mean leaf area consumed by Spodopteralitura and Spilosoma obliqua larva. Phenols and flavonoid content in methanolic leaf extract of thirty three genotypes of soybean were determined by spectrophotometrically. The highest and lowest phenolic content were found in genotypes JS-20-41(2.2 $\pm 0.073 \mathrm{mg} / \mathrm{g})$ and CSB $904(0.45 \pm 0.11$ $\mathrm{mg} / \mathrm{g}$ ), respectively. While the highest and lowest flavonoid content was found in genotypes SL $9794.686 \pm 0.062$ mg QE/ g, respectively. In correlation study a highly significant negative correlation was observed between mean leaf area consumed $\left(\mathrm{cm}^{2}\right)$ by $S$. litura, phenol content $(-0.741)$ and flavonoid content $(-0.737)$ similarly a highly significant negative correlation was observed between mean leaf area consumed by $S$. obliqua, phenol content $(-0.728)$ and flavonoid content $(-0.736)$ in leaves. Hence it can be concluded that, the genotypes which were having higher phenol and flavonoid content in their leaves offered resistance against S. litura and S. boliqua in soybean.
\end{abstract}

Keywords: Flavonoids, Phenols, Soybean, Spodopteralitura, Spilosoma obliqua

\section{INTRODUCTION}

Soybean [Glycine $\max$ (L.) Merrill] is known as "Golden bean", it is a versatile and enthralling crop with countless possibilities of not only getting better agriculture but also supporting industries (Ali, 2008). It contains primary organic and inorganic metabolites such as protein, oil, carbohydrates, minerals and secondary metabolites such as alkaloids and phenolics, including lignin and isoflavones. Primary metabolites are essential for growth, development, and reproduction, but secondary metabolites such as phenolics are associated with plant defense and survival mechanisms under biotic and abiotic stress environment factors such as drought, heat, herbivory and diseases.Phenolics, including phenolic acid, lignin, flavonoids and isoflavones, have been reported to have significant role in seed mechanical damage resistance and disease resistance. Flavonoidsare one of the largest classes of plant phenolic and it develop a defence mechanism in plants for biotic and abiotic stress, like production of flavonoids in plants increases as a result of the exposer to UV-B radiation, it may offer a measure of protection by screening out harmful UV-B radiation (Saviranta et al., 2010). Most plants contain an array of flavonoids, whose fingerprints often differ among families, genera and species. Tannins are phenolic compounds found in the leaves of numerous plant species that are known to defend plants against attack from herbivores (Barbehenn et al., 2006). It is found that the phenolic compounds play an important role in plant resistance through antioxidant activity and free radical scavenging activity against pathogens which are intimately connected with reactive oxygen species (Mittapalliet al., 2006). The plants produce a high diversity of natural products or secondary metabolites with a prominent function in the protection against predators and microbial pathogens on the basis of their toxic nature and repellence to herbivores and microbes (Schafer et al., 2009).

Thus, the aim of this study was to examine leaf extracts of thirty three soybean genotypes for their phenol and flavonoid content as antifeedent compounds and to find out their correlation with mean leaf area consumed by Spodopteralitura and Spilosoma obliqua, so as to conclude that whether phenol and flavonoid contents in soybean plant act as resistant factor or not.

\section{MATERIALS AND METHODS}

The experiment was conducted in Department of Entomology and Department of Plant breeding and genetics GovindBallabh Pant University of Agriculture and Technology, Pantnagar.

Plant materials: Plant material ( leaves )of thirty three genotypes viz., CSB 904, DS 2705, DS 2706, DS 2708, DSb 19, DSb 21, JS 20-41, JS 20-69, JS 20-71, KBS 22-2009, KDS 378, KDS 695, KDS 699, KDS 705, KDS 708, MACS 1340, MACS 1394, MACS 
1407, MACS 1416, MAUS 612, MAUS 614, NRC 92 , NRC 93, NRC 94, PS 1518, RKS 113, RVS-2001-18, SL 958, SL 979, SL 982, SL 688, PS 1092, PS 1347 of soybean were obtained from Crop Research Centre Pantnagar. The leaves were shade dried and vacuum packed until used.

Chemicals: Methanol, Standards of phenolic acids (gallic acid) and of flavonoids (quercetin), Folin- Ciocalteu's phenol reagent, aluminium chloride ( $\mathrm{AlCl} 3$ ), was procured from Sigma Chemical Co. All other chemicals used were of analytical grade and purchased locally.

Preparation of leaf extracts: Leaf extracts were prepared according to a standard protocol. Prepared dry leaf powder $(5 \mathrm{~g})$ was transferred to dark-coloured flasks and mixed with $100 \mathrm{ml}$ of methanol and stored at room temperature. After $24 \mathrm{~h}$, infusions were filtered through Whatman No. 1 filter paper and residue was re-extracted with equal volume of solvents. After $48 \mathrm{~h}$, the process was repeated. Combined supernatants were evaporated to dryness under vacuum at $40{ }^{\circ} \mathrm{C}$ using Rotary evaporator. The obtained extracts were kept in sterile sample tubes and stored in a refrigerator at $4{ }^{\circ} \mathrm{C}$.

Determination of total phenolic contents in the leaf extracts: The concentration of phenolics in leaves extracts was determined using spectrophotometric method (Singleton and Rossi, 1999)with modifications. Methanolic solution of the extract in the concen- tration of $1 \mathrm{mg} / \mathrm{ml}$ was used in the analysis. The samples were thereafter incubated in a thermostat at $45^{\circ} \mathrm{C}$ for $45 \mathrm{~min}$. The absorbance was determined using spectrophotometer at $\lambda \max =765 \mathrm{~nm}$. Same procedure was repeated for the standard solution of gallic acid and the calibration line was construed

Determination of flavonoid concentrationsin theleaf extracts: The content of flavonoids in leaves extracts was determined using spectrophotometric method (Quettier et al., 2000) with slight modifications. The sample contained $1 \mathrm{ml}$ of methanol solution of the extract in the concentration of $1 \mathrm{mg} / \mathrm{ml}$ and $1 \mathrm{ml}$ of $2 \% \mathrm{AlCl}_{3}$ solution dissolved in methanol. The absorbance was determined using spectrophotometer at $\lambda \max =415 \mathrm{~nm}$.

No choice experiment: The antifeedant activity of 33 genotypes of soybean was evaluated against $4^{\text {th }}$ instar larvae of $S$. lituraand $S$. obliqua under laboratory conditions $\left(29 \pm 5^{\circ} \mathrm{C}\right.$, RH $\left.83 \pm 5 \%\right)$ using 'no-choice' feeding technique (Belles et al., 1985 and Kumar, 1993).

Statistical analysis: The experiments were conducted in completely randomized design (CRD) (Gomez and Gomez, 1984) and the means were separated by using STPR 3 software. The correlation between different parameter was analyzed by using STPR-5 software.

\section{RESULTS AND DISCUSSION}

The total phenol content in the leaves extract of soy-

Table 1. Total phenolic and flavonoids content in soybean genotypes.

\begin{tabular}{|c|c|c|c|}
\hline S.N. & Genotypes & Phenolics(mg/g) & Flavonoids (mg/g) \\
\hline 1 & CSB 904 & $0.45 \pm 0.011$ & $0.91 \pm 0.004$ \\
\hline 2 & DS 2705 & $0.90 \pm 0.008$ & $1.96 \pm 0.027$ \\
\hline 3 & DS 2706 & $1.22 \pm 0.011$ & $2.31 \pm 0.028$ \\
\hline 4 & DS 2708 & $1.45 \pm 0.044$ & $2.78 \pm 0.021$ \\
\hline 5 & DSb 19 & $1.27 \pm 0.043$ & $2.55 \pm 0.022$ \\
\hline 6 & DSb 21 & $1.52 \pm 0.015$ & $3.56 \pm 0.039$ \\
\hline 7 & JS-20-41 & $2.20 \pm 0.073$ & $4.22 \pm 0.030$ \\
\hline 8 & JS-20-69 & $1.56 \pm 0.050$ & $3.31 \pm 0.060$ \\
\hline 9 & JS-20-71 & $0.50 \pm 0.045$ & $1.02 \pm 0.032$ \\
\hline 10 & KBS-22-2009 & $1.09 \pm 0.035$ & $2.09 \pm 0.009$ \\
\hline 11 & KDS-378 & $0.63 \pm 0.037$ & $1.32 \pm 0.056$ \\
\hline 12 & KDS-693 & $1.24 \pm 0.021$ & $2.90 \pm 0.053$ \\
\hline 13 & KDS-699 & $0.81 \pm 0.002$ & $1.59 \pm 0.014$ \\
\hline 14 & KDS 705 & $1.46 \pm 0.051$ & $2.58 \pm 0.047$ \\
\hline 15 & KDS 708 & $1.60 \pm 0.002$ & $3.18 \pm 0.022$ \\
\hline 16 & MACS 1340 & $0.62 \pm 0.020$ & $1.18 \pm 0.021$ \\
\hline 17 & MACS 1394 & $0.58 \pm 0.016$ & $1.16 \pm 0.009$ \\
\hline 18 & MACS 1407 & $0.87 \pm 0.027$ & $1.69 \pm 0.028$ \\
\hline 19 & MACS 1416 & $0.94 \pm 0.029$ & $1.89 \pm 0.036$ \\
\hline 20 & MAUS 612 & $1.68 \pm 0.008$ & $3.76 \pm 0.017$ \\
\hline 21 & MAUS 614 & $0.93 \pm 0.026$ & $1.80 \pm 0.024$ \\
\hline 22 & NRC 92 & $1.17 \pm 0.028$ & $2.79 \pm 0.029$ \\
\hline 23 & NRC 93 & $1.22 \pm 0.033$ & $2.56 \pm 0.043$ \\
\hline 24 & NRC 94 & $0.61 \pm 0.030$ & $1.17 \pm 0.061$ \\
\hline 25 & PS 1518 & $0.88 \pm 0.024$ & $1.73 \pm 0.031$ \\
\hline 26 & RKS 113 & $1.22 \pm 0.027$ & $2.78 \pm 0.029$ \\
\hline 27 & RVS 2001-18 & $1.75 \pm 0.057$ & $3.98 \pm 0.031$ \\
\hline 28 & SL 958 & $1.23 \pm 0.008$ & $3.53 \pm 0.014$ \\
\hline 29 & SL 979 & $1.99 \pm 0.009$ & $4.69 \pm 0.062$ \\
\hline 30 & SL 982 & $1.26 \pm 0.006$ & $3.51 \pm 0.067$ \\
\hline 31 & SL 688 & $1.39 \pm 0.041$ & $2.88 \pm 0.045$ \\
\hline 32 & PS 1092 & $0.90 \pm 0.031$ & $1.83 \pm 0.006$ \\
\hline 33 & PS 1347 & $1.27 \pm 0.041$ & $3.57 \pm 0.056$ \\
\hline
\end{tabular}

Values are expressed as mean values of three replications \pm standard deviation 


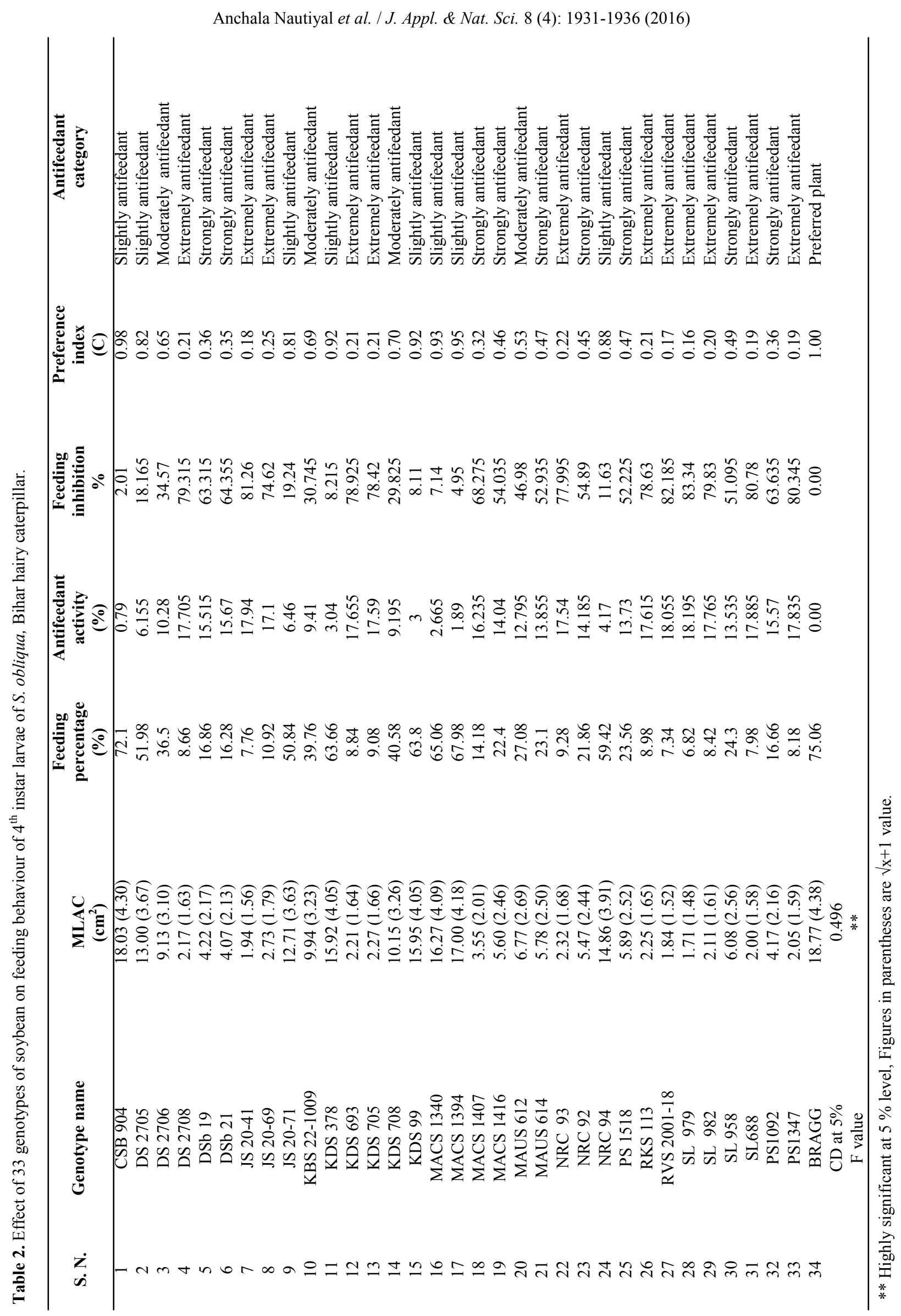




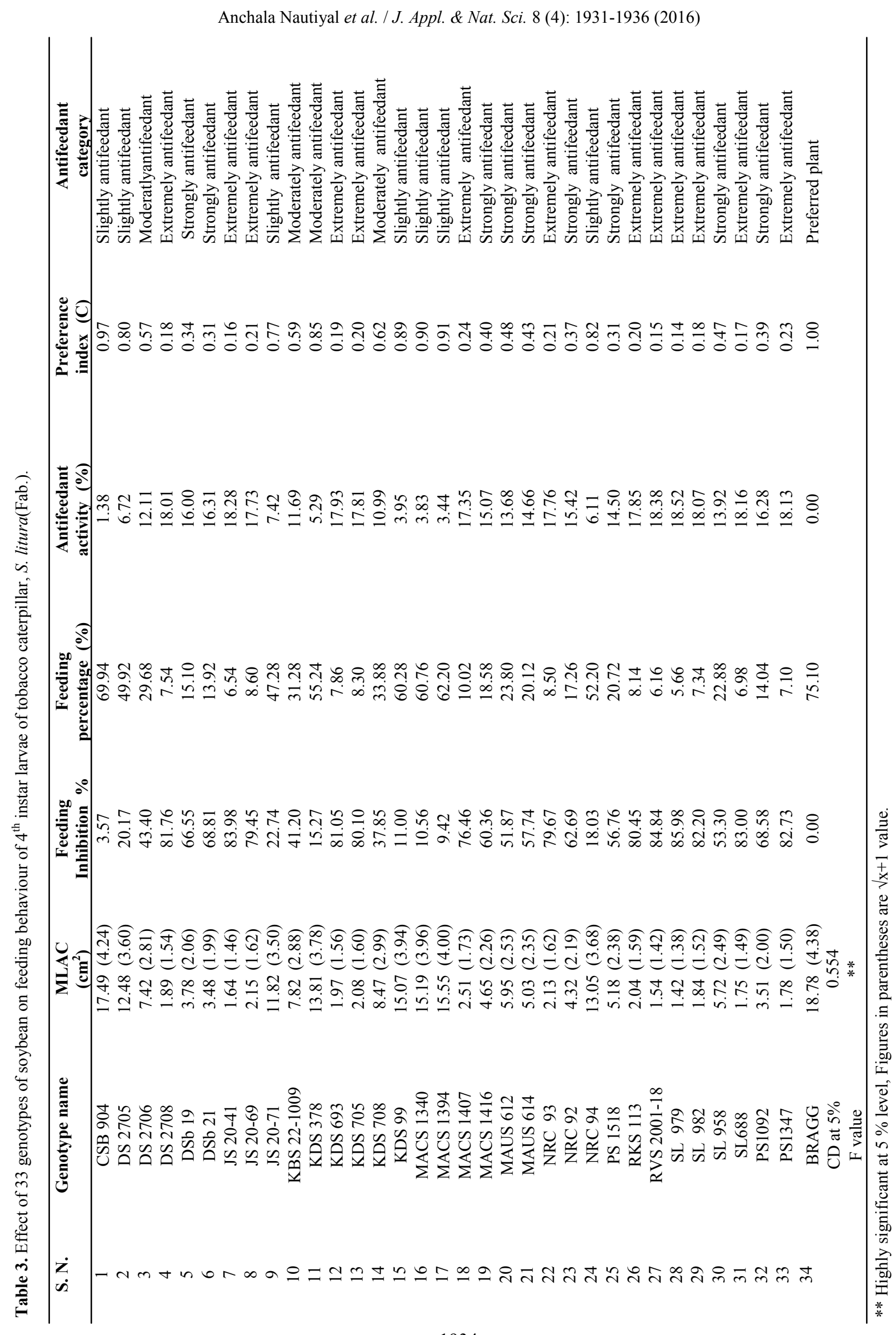


Table 4. Simple correlation coefficient between biochemical constituents of soybean genotypes leaves and mean leaf area consumed $\left(\mathrm{cm}^{2}\right)$.

\begin{tabular}{ccc}
\hline $\begin{array}{c}\text { Chemical } \\
\text { com- } \\
\text { pounds }\end{array}$ & $\begin{array}{c}\text { Mean leaf area } \\
\text { consumed by } \boldsymbol{S} . \\
\text { litura }\end{array}$ & $\begin{array}{c}\text { Mean leaf area con- } \\
\text { sumed by } \boldsymbol{S} \text {. obliqua }\end{array}$ \\
\hline Phenols & $-0.741^{* *}$ & $-0.728^{* *}$ \\
Flavonoids & $-0.737 * *$ & $-0.736^{* *}$ \\
\hline
\end{tabular}

** Highly significant at $1 \%$

bean genotypes was expressed as $\mu$ moles gallic acid equivalent (GAE) per gram extract. The phenol content in the leaves varied from $2.2 \pm 0.073$ to $0.45 \pm 0.011$ $\mathrm{mg} / \mathrm{g}$ of leaves extract Table 1 . The highest phenolic content recorded in genotypes JS-20-41(2.2 \pm 0.073 $\mathrm{mg} / \mathrm{g}$ ) followed by SL 979, RVS 2001-18, MAUS 612, with $1.998 \pm 0.009,1.751 \pm 0.057$ and $1.69 \pm 0.008 \mathrm{mg} /$ $\mathrm{g}$ respectively, whereas, the lowest total phenolic content recorded in genotypes namely CSB 904 (0.45 $\pm 0.11 \mathrm{mg} / \mathrm{g}$ ) followed by $0.500 \pm 0.045,0.583 \pm 0.016$, $0.612 \pm 0.030,0.622 \pm 0.020 \mathrm{mg} / \mathrm{g}$ of leaf extract respectively for JS 20-71, MACS 1394, NRC 94, MACS 1340 genotypes.

Flavonoids are also one of important biochemical component for protection crop against herbivores. The flavonoid content was expressed as $\mu$ mole Quercetin Equivalents (QE) g- ${ }^{1}$ dry wt. Total flavonoid content in methanolic soybean leaf extract ranged from $0.913 \pm$ 0.004 to $4.686 \pm 0.062 \mathrm{mg} \mathrm{QE} / \mathrm{g}$ Table 1 . The genotypes differed with respect to flavonoid content in their leaf extract. Maximum flavonoids recorded in genotypes SL $9794.686 \pm 0.062 \mathrm{mg} \mathrm{QE} / \mathrm{g}$ followed by $4.225 \pm 0.030,3.976 \pm 0.031$ and $3.560 \pm 0.039 \mathrm{mg} \mathrm{QE} / \mathrm{g}$ for JS -20-41, RVS 2001-18 and DSb 21 and PS 1347 respectively for leaf extract of soybean genotypes. Minimum total flavonoids were observed in CSB 904 $(0.913 \pm 0.004 \mathrm{mg} \mathrm{QE} / \mathrm{g})$ followed by JS 20-71 (1.022 \pm 0.032$)$, MACS $1394(1.160 \pm 0.009)$, MACS $1340(1.181 \pm 0.021)$ and NRC $94(1.18 \pm 0.061) \mathrm{mg}$ $\mathrm{QE} / \mathrm{g}$ of leaf extract respectively.

In no choice feeding experiment for $S$. litura the minimum feeding was observed with SL $979\left(1.42 \mathrm{~cm}^{2}\right)$ and maximum in CSB $904\left(17.48 \mathrm{~cm}^{2}\right)$ over check (Bragg=18.77 $\mathrm{cm}^{2}$ ), while the minimum and maximum feeding was found withSL $979\left(1.71 \mathrm{~cm}^{2}\right)$, and CSB $904\left(18.03 \mathrm{~cm}^{2}\right)$ respectively against larvae of $S$. obliqua over control (MLAC $=18.76 \mathrm{~cm}^{2}$ ). On the basis of preference index DS 2708, JS 20-41, JS 20-69, KDS 693, KDS 705, NRC 93, RKS 113, RVS 113, RVS 2001-18, SL 979, SL 982, SL 688 and PS 1347 genotypes were found to be extremely antifeedant while DSb 19, DSb 21, MACS 1407,MACS 1416, MAUS 614, NRC 92, PS 1518, SL 958 and PS 1092 were found strongly antifeedant and DS 2706, KBS 22-
2009, KDS 708 and MAUS 612 were found to be moderately antifeedant, while the remaining genotypes where found slightly antifeedant Tables 2 and 3 .

In the present study a fairly high degree of association was found between mean leaf area consumed and with some of important biochemical constituents in soybean genotypes Table 4. A highly significant and negative correlation was observed between MLAC $\left(\mathrm{cm}^{2}\right)$ by S.litura and S.obliqua and Phenol content in leaves $(\mathrm{r}=$ $0.741 * *)$ and $(-0.728 * *)$ respectively, flavonoid content in leaves $\left(\mathrm{r}=-0.737^{* *}\right)$ and $\left(-0.736^{* *}\right)$, respectively.

Thus it can be concluded that the genotypes which were having higher biochemical parameters namely Phenol and flavonoids in their leaves offered resistance against S.litura and S.boliqua in soybean. Other authors also found that phenols and falvonoids plays aimportant role in plant defence system. (War et al., 2011) reported that the plant phenol constitute one of the most common and widespread group of defensive compound which play a major role in host plant resistance against herbivores, including insects. Phenol limits the entry of herbivore by blocking physically or increasing the leaf toughness that reduces the feeding by herbivors, and also decreases the nutritional content of the leaf (Johnson et al., 2009). The concentration of the toxic phenolic compounds in the plant is a key factor in deterrence and it is the accumulation of phenols in particular parts of the plant which represent a feeding barrier (Castellanos and Espinosa, 1997 and Zagrobelnyet al., 2004). (Simmonds and Stevensoni, 2001) reported that flavonoids shows antifeedant and antibiotic activity towards the larvae of $H$. armigera. (Kondo et al., 1992) also concluded that flavonoids areone of the largest classes of plant phenolic and perform very different functions in plant system including pigmentation and defense from insect herbivory. Girijaet al.(2008) reported that total phenols exhibited highly significant negative association $(-0.763)$ with per cent pod damage followed by cellulose $(-0.706)$, malic acid (-0.684), pod husk thickness (-0.668), lignin ($0.627)$ and number of trichomes $(-0.596)$, while hemicellulose showed negative correlation $(-0.266)$ with per cent pod damage although non-significant.Handley et al. (2005) reported that trichome density negatively affects the ovipositionalbehavior, feeding and larval nutrition of insect pests. In addition, dense trichomes affect the herbivory mechanically, and interfere with the movement of insects and other arthropods on the plant surface, thereby, reducing their access to leaf epidermis (Howe and Jander 2008). The Glandular trichomes secrete secondary metabolites including flavonoids, terpenoids, and alkaloids that can be poisonous, repellent, or trap insects and other organisms, thus forming a combination of structural and chemical defense (He et al., 2011).

\section{Conclusion}

A highly significant negative correlationswas observed 
between mean leaf area consumed $\left(\mathrm{cm}^{2}\right)$ by S.litura $(-$ $0.741)$ and S.obliqua (-0.728)and Phenol (-0.737) \& flavonoid (-0.736) content in leaf extract of soybean genotypes respectively. Thus it can be concluded that, the genotypes which were having higher Phenol and flavonoid content in their leaves offered resistance against S.litura and S.boliqua in soybean.

\section{ACKNOWLEDGEMENTS}

Authors are grateful to "Indian Council of Medical Research (ICMR)" for awarding Senior Research fellowship to first author for her Ph.D. research. Authors are also thankful to Dean Agriculture, GovindBallabh Pant University of Agriculture and Technology, Pantnagar, for providing the necessary facilities and support for carrying out the study successfully.

\section{REFERENCES}

Ali, N. (2008). Soybean the golden grain of the globe. 5th international soybean processing and utilization conference ISPUC-V, CIAE, Bhopal, India, pp: 1-4

Barbehenn, R.V., Jones, C. P., Karonen, M. and Salminen, J.P. (2006). Tannin composition affects the oxidative activities of tree leaves. Journal of Chemical Ecology. 32: $2235-2251$

Belles, X., Camps, F., Coil, J. and Piulachs, M.D. (1985). Insect antifeedant activity of clerodanediterpenoids against larvae of Spodopteralittoralis(Boisd.) (Lepidoptera). Journal of Chemical Ecology, 11:14391445

Castellanos, I. and Espinosa, G.F.J. (1997). Plant secondary metabolite diversity as a resistance trait against insects: a test with Sitophilusgranarius (Coleoptera: Curculionidae) and seed secondary metabolites. Biochem. Syst. Ecol., 25: 591-602

Girija.,Salimath, P.M., Patil, S.A., Gowda, C.L.L. and Sharma, H.C. (2008). Biophysical and biochemical basis of host plant resistance to pod borer (Helicoverpaarmigera Hub.) in chickpea (CicerarietinumL.). Indian J. Genet., 68 (3): 320-323

Gomez, K.A. and Gomez, A.A. (1984). Statistical procedures for agricultural research. Second edition. John Wiley and Sons, New York.

Handley, R., Ekbom, B. and Agren, J. (2005). Variation in trichome density and resistance against a specialist insect herbivore in natural populations of Arabidopsis thaliana. Ecol Entomol, 30:284-292

He, J., Chen, F., Chen. S., Lv, G., Deng, Y. and Fang, W. (2011). Chrysanthemum leaf epidermal surface mor- phology and antioxidant and defense enzyme activity in response to aphid infestation. Journal of Plant Physiology., 168:687-693

Howe, G.A. and Jander, G. (2008). Plant immunity to insect herbivores. Annu Rev Plant Biol., 59:41-66

Johnson, M.T.J., Smith, S.D. and Rausher, M.D. (2009). Plant sex and the evolution of plant defenses against herbivores. ProcNatlAcadSci U S A. 106:18079-18084.

Kondo, T., Yoshida, K., Nakagawa, A., Kawai, T., Tamura, H. and Goto, T. (1992). Structural basis of blue-color development in flower petals from commelinacommunis. Nature, 358: 515-518

Kumar, S. (1993). Feeding deterrent and insecticidal activity of weed plants from tarai region against Henosepilachnavignitioctopuntata(Fab.).Thesis, M.Sc.(Ag.), G.B.Pant University of Agriculture and Technology, Pantnagar,pp 82.

Mittapalli, O., Shukle, R.H. and Neal, J. (2006). Antioxidant defense response in the Hessian fly (Diptera: Cecidomyiidae). National Entomological Society of America Annual Meeting, 104: 1889-1894

Quettier, D.C., Gressier, B., Vasseur, J., Dine, T., Brunet, C., Luyckx, M.C.,Cayin, J.C., Bailleul, F. and Trotin, F. (2000). Phenolic compounds and antioxidant activities of buckwheat (Fagopyrum esculentum Moench) hulls and flour. J.Ethnopharmacol, 72, 35-42

Saviranta, N.M., Jukunen-Titto, R., Oksanen, E. and Karjalainen, R.O. (2010). Leaf phenolic compounds in red clover (TrfoliumPratense L.) induced by exposure to moderately elevated ozone. Environmental Pollutio, 158(2): 440-446

Schafer, H. and Wink, M. (2009). Medicinally important secondary metabolites in recombinant microorganisms or plants: progress in alkaloid biosynthesis. Biotechnology Journal, 4(12): 1684-1703

Simmonds, M.S.J. and Stevenson, P.C. (2001). Insect Antifeedant Activity of Three New Tetranortriterpenoids from Trichilia p allida. J. Chem. Ecol., 27 (5), 965-968

Singleton, V.L. and Rossi, J.A. (1999). Colorimetry of total phenolics with phosphomolybdic-phosphotungstic acid reagents. American Journal of Enologyand viticulture., 16: 144-158

War, A.R., Paulraj, M.G., War, M.Y. and Ignacimuthu, S. (2011) Herbivore and elicitor-induced resistance in groundnut to Asian armyworm, Spodopteralitura (Fab.) (Lepidoptera: Noctuidae) Plant Signal Behav, 6:17691777

Zagrobelny, M., Bak, S., Vinther, R.A., Jørgensen, B., Naumann, C.M., and Lindberg, M.B. (2004). Cyanogenicglucosides and plant-insect interactions. Phytochemistry, 65:293-306 